\title{
Rapunzel Alopecia: A Peculiar Form of Non-Marginal Traction Alopecia Secondary to Excessively Long Hair
}

\author{
Alejandro Lobato-Berezo Sara Tormo-Mainar Ramón M. Pujol \\ Department of Dermatology, Hospital del Mar-Parc de Salut Mar, Barcelona, Spain
}

\section{Established Facts}

- Traction alopecia is secondary to chronic tensile forces on the hair due to different hairstyles with two main clinical forms, marginal and non-marginal.

\section{Novel Insights}

- Non-marginal traction alopecia (TA) may also be secondary to the excessive weight of a very long, non-manipulated hair.

- Pathology and trichoscopy of this mechanism of TA are provided in the article.

\section{Keywords}

Traction alopecia $\cdot$ Rapunzel $\cdot$ Cicatricial alopecia

\section{Abstract}

Traction alopecia (TA) is an underreported scarring alopecia in children and adolescents. TA occurs from chronic tensile forces on the hair and can be caused by different hairstyles that pull the hair tightly, such as regularly wearing braids, ponytails, cornrows, dreadlocks, and weaves, or by treating hair with rollers, hair extensions, or chemical relaxers.

(c) 2020 S. Karger AG, Basel

\section{Introduction}

Traction alopecia (TA) is an underreported scarring alopecia in children and adolescents. TA occurs from chronic tensile forces on the hair and can be caused by different hairstyles that pull the hair tightly, such as regularly wearing braids, ponytails, cornrows, dreadlocks, or weaves, or by treating the hair with rollers, hair extensions, or chemical relaxers [1]. A case of TA, most probably secondary to the excessive weight of non-manipulated, normal hair, pulling on the scalp, is reported.

A healthy, 17-year-old girl with a very long hair presented with a patch of alopecia in the middle of the scalp, from several months. No other patches of alopecia could be seen on the scalp or on the rest of the body. When asked about her hair practices, she told that she combed

$\begin{aligned} & \text { karger@karger.com } \\ & \text { www.karger.com/sad }\end{aligned}$
Karger ${ }^{\prime /}$

Alejandro Lobato-Berezo

Department of Dermatology, Hospital del Mar-Parc de Salut Mar Passeig Marítim, 25-29

ES-08003 Barcelona (Spain)

allobe@ hotmail.es 
Fig. 1. a Long mane, more than $100 \mathrm{~cm}$ long. b Irregular, $10-\mathrm{cm}$ patch of alopecia in the middle of the scalp.

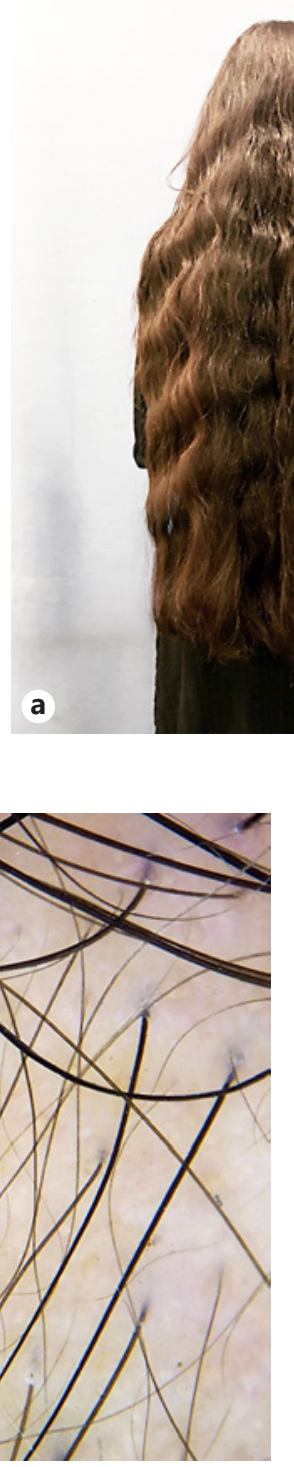

Fig. 2. Trichoscopy: empty follicles (blue arrowheads), different hair shaft diameters (green dots), and hair casts (red asterisks).

and brushed her long hair daily, always with the same pattern, and she denied using hot combs, relaxers, tight extensions, or weaves. She denied picking or pulling her hair, and she did not experience any pain, discomfort, or trichodinia. No previous history of psychological or psychiatric disorders was recorded. Physical examination revealed a $100-\mathrm{cm}$, long, wavy, normal-looking, brown hair (Fig. 1a). An irregular, linear, 10-cm patch of alopecia that extended from the frontal line to the vertex, through the middle of the scalp, was observed (Fig. 1b). Trichos-

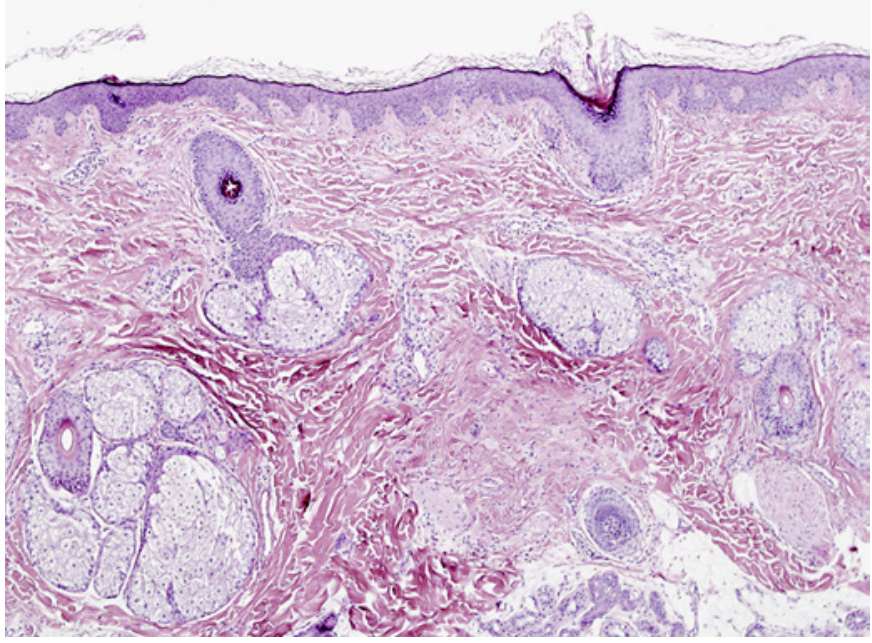

Fig. 3. Hematoxylin-eosin $\times 40$ : mild perifollicular fibrosis and perivascular inflammatory infiltrate with lymphocytes. Note trichomalacia.

copy showed empty follicles, and different hair shaft diameters and hair casts (Fig. 2). No erythema, peripilar hyperkeratosis, exclamation mark hairs, and yellow or black dots were seen. No trichoscopic signs of trichotillomania were appreciated (shafts of varying lengths, broken hairs, trichoptilosis, coiled or hook hairs, V-sign, perifollicular hemorrhages, and hair powder). A biopsy showed an increased vellus hair/terminal hair ratio with trichomalacia, mild perifollicular fibrosis, and a perivascular inflammatory infiltrate composed of lymphocytes. 
The presence of normal sebaceous glands ruled out the diagnosis of primary scarring alopecia. No perifollicular inflammatory infiltrate was found (Fig. 3). With the diagnosis of TA, we suggested wearing a shorter hair and changing her combing pattern with a loose ponytail to reduce hair weight and change the traction, plus the application of $5 \%$ minoxidil foam at nights.

TA is well recognized in adults but may be unnoticed in children and adolescents. The prevalence of TA is higher in people who wear tight knot turbans, ponytails, or buns, which is influenced by hair phenotype, fashion, cultural, and religious factors [1]. This risk is increased with the extent of pulling and the duration of traction [2].

TA is divided into 2 main clinical forms: marginal and non-marginal [3]. Marginal TA is characterized by a loss or thinning of hair in a band-like pattern, just behind the hairline at the frontal or temporal scalp, which has to be differentiated from ophiasic alopecia areata and frontal fibrosing alopecia [2]. Non-marginal TA is less frequent than the latter and is characterized by hair loss outside the hairline, often related to chronic traction from styling (buns or hair extensions) $[3,4]$. Development of nonmarginal TA in individuals with very long hair due to the weight of the hair pulling on the scalp seems to be a rare event that has received little attention in the literature.

Isolated cases of TA in children have been reported; 2 Sikh male adolescents who wore turbans and 2 five- and 4 -year-old girls after pressure ischemia and acute TA developed TA after elaboration of professional hair stylings $[4,5]$. One series revealed an overall proportion of $9.4 \%$ of TA in African schoolchildren [6]. In contrast to previously reported cases, our patient presented an excessively dense and long hair and developed TA without applying any hair straightening technique. Most probably, the observed non-marginal TA was secondary to the excessive weight of a normal hair pulling on the scalp. The descriptive term "Rapunzel alopecia" seems to illustrate this particular phenomenon.
Treatment of TA requires conservative measures in the early stages (changes in the hairstyle, and avoidance of chemical and thermal treatments). Late stages need medical and surgical interventions such as topical minoxidil or hair transplantation [3].

\section{Conclusion}

In conclusion, we report a case of non-marginal TA with distinctive features in a 17-year-old girl. We would like to highlight the possibility that heavy weight of the hair may induce TA in patients with an excessively long hair and to emphasize the importance of prompt recognition of this particular, most probably underreported, disorder.

\section{Statement of Ethics}

The authors state that they have complied with the guidelines for human studies and the study was conducted ethically in accordance with the World Medical Association Declaration of Helsinki. The patient gave her written informed consent to publish the case with the pictures.

\section{Disclosure Statement}

The authors have no conflicts of interest to declare.

\section{Funding Sources}

No funding sources were required.

\section{Author Contributions}

A.L.-B. visited the patient and wrote the manuscript. S.T.-M. made the pictures and contributed to the manuscript elaboration. R.M.P. reviewed the mansucript.

\section{References}

1 Samrao A, Price V, Zedek D, Mirmirani P. The "Fringe Sign": a useful clinical finding in traction alopecia of the marginal hair line. Dermatol Online J. 2011;17:1.

2 Agrawal S, Daruwalla SB, Dhurat RS. The flambeau sign: a new dermoscopy finding in a case of marginal traction alopecia. Australas J Dermatol. 2020 Feb;61(1):49-50.
3 Ozçelik D. Extensive traction alopecia attributable to ponytail hairstyle and its treatment with hair transplantation. Aesthetic Plast Surg. 2005;29:325-7.

4 Zimmerman B, Ivars M, Cordoro KM. Bibbidi bobbidi bald: two "hairowing" tales of Princess Package hairstyles. Pediatr Dermatol. 2018;35:415-7.
5 Karimian-Teherani D, El Shabrawi-Caelen L, Tanew A. Traction alopecia in two adolescent Sikh brothers: an underrecognized problem unmasked by migration. Pediatr Dermatol. 2011;28:336-8.

6 Khumalo NP, Jessop S, Gumedze F, Ehrlich R. Hairdressing is associated with scalp disease in African schoolchildren. Br J Dermatol. 2007;157:106-10.
Rapunzel Alopecia: A Peculiar Form of Non-Marginal Traction Alopecia
Skin Appendage Disord 2020;6:323-325 DOI: $10.1159 / 000508727$ 